\title{
Status of women surgeons in Japan
}

\author{
Patricia Joy Numann
}

Received: 17 December 2012/ Accepted: 21 January 2013/Published online: 28 May 2013

(C) Springer Japan 2013

Keywords Women surgeons · Equality

Societies where women have been fully integrated into the education, political and health systems, as well as the workforce, are economically and politically more stable than those where this has not occurred. By establishing the Gender Equality Bureau of the Cabinet Office, the Japanese government clearly recognizes the need of this benefit in Japan. Dr. Yasuko Tomizawa, in her article [1] reporting the results of two surveys of the women surgeons of Japan, has shown the lack of professional equality in surgery and the limited progress over the ensuing 3 years. The inclusion of women must involve a conscious effort, and not be expected to occur by chance. Until equity is achieved, any discussion on barriers and evaluation of the status of women in surgery must be public. Removal of the topic from the Japan Surgical Society is disheartening. Mixing the issues with more generic topics will not give this issue proper visibility and expresses the lack of concern over the status of women. As women now occupy a greater percent of the medical school positions, they must select surgery with the same frequency as men or the specialty will be understaffed and will decline in intellectual ability. Enlightened men understand the issue.

They hope their daughters, sisters and wives will also pursue the career they have loved. They can and should advance the cause as well as women. Women will vote with their feet as they appear to have been doing by selecting other fields where they have a greater chance for advancement. Sociologic data suggest that to have a meaningful voice, one-third of the leadership should represent the minority group. Hopefully, that will be the shortterm goal of the surgical societies of Japan and will be reflected in the next survey report.

Conflict of interest Patricia Numann has no conflict of interest.

\section{Reference}

1. Tomizawa Y. Women in surgery: little change in gender equality in Japanese medical societies over the past 3 years. Surg Today. 2012. doi:10.1007/s00595-012-0447-7.
P. J. Numann $(\bowtie)$

Upstate Medical University, Syracuse, NY, 323 Highland Ave,

Syracuse, NY 13203, USA

e-mail: numannp@upstate.edu 